\title{
Investigating the Role of Cultural Capital and Organisational Habitus in Architectural Education: A Case Study Approach
}

\author{
Jennifer Chamberlin Payne
}

\begin{abstract}
Compared to other professions in recent years, architecture has lagged woefully behind in attracting and retaining a diverse population, as defined by class, race and gender. This research investigates the extent to which architecture culturally reproduces itself, specifically examining the socialisation process of students into the subculture of architecture during formal education. The work of French sociologist and anthropologist Pierre Bourdieu, who has written extensively on the subject of socialisation in education, serves as a theoretical framework for this research. Specifically, two factors are examined in this study: a student's level of cultural capital and the organisational habitus of the architecture programme. Using a comparative case study research strategy of two US schools of architecture, both quantitative and qualitative tactics are employed to provide a rich description of architecture students' and faculties' experiences. Building upon cultural reproduction and cultural mobility theories, findings from this research present a more nuanced under-
\end{abstract}

standing of students' backgrounds, beyond the typical dichotomous definition of high vs low cultural capital. Recommendations are made for architectural education to consider meaningful curricular reform in an effort to attract and engage a more diverse student population.

\section{Keywords}

architectural education, sociology of education, cultural capital, habitus, diversity 
Introduction

It is readily apparent from a brief perusal of the sociology of education literature that no formal education is exempt from socialising its students Karabel \& Halsey 1977). This is not to say that students are solely passive receivers in this process, but instead, they do enter formal education with past experiences, a history and an accumulated body of knowledge, as well as multiple identities. Sociologists have addressed the issue of inequalities and socialisation in professional programmes of higher education, such as law and medicine, but this subject has been relatively overlooked in architecture. In the present research, I am solely focused on the realm of architectural education to investigate the extent to which inequalities exist in the cultural reproduction of architectural education, employing quantitative and qualitative methods at two US public schools of architecture. The work of French sociologist and anthropologist Pierre Bourdieu serves as a framework and lens of analysis in this research. Students inevitably have varied experiences throughout their educations and this work researches the extent to which such variations are systematically related to a student's level of cultural capital or habitus, which may either foster or hinder his or her ability to acclimate to the subculture of architecture.

\section{Context of research}

Using a Bourdieuian lens, I am specifically questioning the extent to which a student's level of cultural capital and the organisational habitus of the student's school of architecture (that is situated within a particular university) shape a student's socialisation in architectural education. These two factors of cultural capital and organisational habitus originate from Bourdieu's theory of cultural reproduction and will be defined as they relate to this study.

\section{Cultural capital}

'Cultural capital' is broadly defined as a representation of one's cultural value, and includes a variety of traits and behaviors, such as posture, dress, language, preferences, academic credentials and social networks that ultimately describe who we are and where we are located in the greater social strata (Bourdieu 1977). Whereas 'class' refers to one's economic standing and financial wealth, 'cultural capital' is a much broader, inclusive descriptor to account for all the other cultural resources we hold. The term 'habitus' is an expansion on the notion of cultural capital, referring to all of the dispositions and attitudes one possesses, that are both learned, and in a sense, inherited from one's upbringing; one's habitus functions as a guide through life, informing decisions, behaviours and habits (Reed-Danahay 2005). Bourdieu conceptualised habitus as a strong and stable system, yet still flexible enough to shift and adapt given new experiences throughout one's lifetime (Bourdieu 1977). Another broad descriptor often used to approximate habitus is that of 'worldview' (Dobbin 2008, 58).

Bourdieu's work is premised on the notion that systems of cultural privilege exist and reproduce themselves without anyone's conscious effort or even awareness. In order fully to understand the pervasiveness and depth of such reproduction in the greater society, Bourdieu argues that the norms and practices of educational institutions must first be examined, as he believed that those institutions held the most power in perpetuating one's level of status and privilege (Swartz 1997). It is Bourdieu's position that schools 'misrecognize' elevated levels of cultural capital as 'natural' talent and in turn reward such students for simply being cultured and having a privileged family background. Bourdieu $(1996,21)$ referred to the idea of 'natural' talent as 'ease' and discussed it as follows:

what we call ease is the privilege of those who, having imperceptibly acquired their culture through a gradual familiarization in the bosom of the family, have academic culture as their native culture and can maintain a familiar rapport with it that implies the unconsciousness of its acquisition.

One self-proclaimed 'architectural sociologist', Garry Stevens, has effectively appropriated Bourdieu's concepts of cultural capital and habi- 
tus in the realm of architectural education, seeking to dispel the myth of 'creative genius' by highlighting the advantages afforded to students who enter this particular system of education with high levels of cultural capital. Stevens (1995, 1998) asserted that Bourdieu is especially useful to studying this situation, for his work on societal status considers how the subtleties of one's being reinforces his or her status in life and membership to a closed, homogeneous group. He argued that the subjective nature of architectural education, unlike law, medicine or engineering, 'requires not only knowing something, but being something' (Stevens 1995, 112). Furthermore, the unique features of architectural education:- for example, the studio system, extensive one-on-one interaction between students and faculty and the reliance on public presentations for student evaluations - continually offer opportunities for students to put themselves, or more aptly in Bourdieuian terms, their habiti, on display.

Stevens $(1995,1998)$ argued that architectural education seeks to, and indeed does, attract and train those individuals whose habitus is already in alliance with the discipline of architecture: that is, those individuals who possess and exhibit high cultural capital inherited from the circumstances of their upbringing. Those who do not come from such a background would quickly and intuitively feel the social unease of being out of one's element in architectural education and, as Stevens suggested, would self-select out. Stevens' work serves as a springboard for the present research, but instead of primarily citing broad sociological data from Australia and the UK to support this position that architectural education serves to 'privilege the privileged' as Stevens did, I have employed a case study approach, with quantitative and qualitative measures to document the experiences of graduating architecture students as individuals in a system preparing them for the discipline of architecture. Although theoretically compelling, Stevens' work has approached the issue of socialisation in architectural education as a dichotomy of high vs low cultural capital, claiming those students with high amounts of cultural capital are likely to reap the benefits of being more prepared for and more at ease in the realm of architectural education. Building upon Stevens' work, I will present evidence of a more complex situation at the two case study sites under consideration, one in which students cannot be simply categorised into either high or low levels of cultural capital.

\section{Organisational habitus}

'Organisational habitus' is a concept that has been adapted from the social reproduction theory of Pierre Bourdieu and refers to 'the classbased dispositions, perceptions, and appreciations transmitted to individuals in a common organizational culture' (Horvat \& Antonio 1999, 320). McDonough (1997) was one of the first researchers of higher education to employ the concept of organisational habitus in her work on the college selection process. In addition to considering a student's level of cultural capital and habitus, she also acknowledged the role that the students' high schools, which varied in resources and prestige, played in shaping a student's college selection. Accounting for a school's organisational habitus allows for a more comprehensive understanding of how schools contribute to reproducing social inequalities in the present research.

\section{Rationale for research}

There are two primary concerns motivating this research on socialisation in architectural education: (1) the perpetuation of a lack of diversity in terms of class, race and gender in the larger architecture discipline and (2) the broader issue of class-based differences in access and equity in systems of US higher education. While both of these issues may have separately received attention among certain academic circles (either architecture or sociology of education, with the latter having more effectively reached out to broader non-academic audiences), previous research has generally not made a connection between the two. I aim to weave these bodies of research together in the present work, drawing on the strengths of both with the intent to encourage all relevant participants in architec- 
tural education (students, faculty and administrators) to be self-critical and question the implicit values inherent in their particular system of education.

\section{Lack of diversity in architecture}

The discipline of architecture has had a longstanding reputation of being a predominantly white, upper class, male profession (Anthony 2002; Groat \& Ahrentzhen 1996). Statistics from the American Institute of Architects (AIA) collected in 2004 at first lead one to believe that schools of architecture have made great progress, at least in the realm of attracting women (American Institute of Architects 2004). The AIA estimates that 40-50 per cent of graduates of architecture schools in the United States are female. However, the numbers steadily decline as women enter (or perhaps more accurately, do not enter) the profession. The AIA estimates that women comprise 33 per cent of associate AIA membership, which includes students and interns, 11 per cent of licensed AIA membership and 20 per cent of all registered architects. Minorities (defined and grouped as 'people of color' by the AIA) are represented even less in the profession, in that they constitute only 19 per cent of associate AIA members, 6 per cent of AIA licensed members and 11 per cent of all registered architects. As one programme director of a US school of architecture said, 'Almost any place in the world is more diverse than an architecture school' (May 2004). Although there are quite possibly a number of other variables that contribute to a lack of diversity in the discipline of architecture (e.g. relatively low pay compared to other professions, job insecurity, difficult work hours and schedules), this research is primarily concerned with the extent to which differing levels of cultural capital play in perpetuating such homogeneity.

\section{Uncovering inequalities in higher education}

There is a larger theme of identifying inequalities in higher education that is embedded within the present research, questioning the perpetuation of privilege within higher education, that is, the substantial numbers of predominantly white, upper class students at institutions of high prestige and similarly large proportions of racial minorities and lower socioeconomic status students at community colleges and less prestigious universities and colleges (Kingston \& Lewis 1990; McDonough 1997). One researcher described this condition thus: 'the academically and socioeconomically "rich" become richer while the academically and socioeconomically "poor" become poorer' (Hearn 1984, 22). Although I am focusing specifically on programmes of architecture in this research, the context within which these architecture programmes are operating cannot be ignored. The two universities I selected for data collection represent different points on a continuum of prestige, with School A being relatively high and School $B$ being relatively low, and they do indeed follow the patterns described above when student demographics are examined. For example, 71 per cent of the entire student body representing all disciplines at School A are white, 5 per cent are Hispanic and 7 per cent are AfricanAmerican; in contrast, at School B, 51 per cent of the student body are white, 35 per cent are Hispanic and 3 per cent are African-American (US News World Report 2007). Additional information from both schools' financial aid departments indicates a large difference in the percentage of students receiving Pell grants, which are US federal grants awarded to economically disadvantaged students, with only 12 per cent at School A compared to 28 per cent at School B.

\section{Research design}

In addressing the question of to what extent a student's cultural capital and architecture school's organisational habitus shape his or her experiences, I have employed a case study research design at two US public schools of architecture. As described by Robert Yin, one of the leading authorities on case study research, this particular research design follows a 'replication logic' in that multiple cases should be considered analogous to multiple experiments; this is in contrast to how case study designs have been mistakenly interpreted in the past using a 'sampling logic' in that multiple cases 
Table 1 Student survey sample response rates

\begin{tabular}{llll}
\hline & $n$ & Total possible students & Response rate \\
\hline School A & 81 & 130 & $62.3 \%$ \\
\hline School B & 46 & 33 & $100 \%$ \\
\hline
\end{tabular}

are analogous to multiple respondents (Yin 1994 , 47). For this research, the two case study sites should be conceptualised as replications, not as a sample size of two. Choosing two case study sites for this research allowed for an in-depth, comprehensive examination of two architecture programmes, giving me the opportunity to examine their unique dynamics in their real world context (Yin 1994). These two case study sites were carefully selected for their differing levels of organisational habiti, with School A being relatively high and School B being relatively low. Measures used to document the schools' organisational habiti included university resources, six year graduation rates, percentage of Pell grant recipients, and entering freshman GPA and SAT scores.

After receiving approval from both schools' Institutional Review Boards, I sent an email request to each programme's architecture student listserv, offering them a brief description of the research and requesting their participation. A written survey was distributed to all graduating architecture students, including both undergraduate and masters' students, at the end of the Spring 2008 semester. Survey questions were primarily modeled after instruments used in previously published research on architectural education such as Groat \& Ahrentzhen (1996), Spreckelmeyer et al. (1985) and Boyer \& Mitgang (1996). In addition to demographic questions and measures of cultural capital, the survey included five banks of questions: Perceived \& Ideal curriculum, Studio experiences, Satisfaction, Problematic experiences and Goals \& Motivations. It also incorporated open-ended questions regarding the strengths and weaknesses of the programme, which helped to further support students' responses to the quantitative survey questions. Response rates for the survey are shown in Table 1. There is a discrepancy to explain between the Total students sampled and the Total 2008 exiting School B students. Since the programme was much smaller at School B than at School A, I invited all students who were in their final studio to participate in the research at School B. Therefore, not all of the students who were sampled in Spring 2008 graduated in that semester, but rather were on schedule to graduate within the following year.

There were 11 measures of cultural capital on the survey, primarily adapted from the studies by Aschaffenburg \& Maas (1997) and Dumais (2002) on the interaction of cultural capital with academic success. Questions of student participation in extracurricular classes (art, music, dance, creative writing) as well as measures of parental cultural capital (highest level of education achieved) and parental involvement (listening to classical music in the home, going to the public library, attending art museums, attending plays, being encouraged to read books outside of school) served as indicators of a student's level of cultural capital.

In addition to the quantitative survey data, I also collected qualitative data in semi-structured interviews with a smaller sample of students and faculty. Initially, only eight students at School A and two students at School B volunteered to participate in interviews. To substantially increase this sample size, I employed a snowball sampling strategy, which involved asking interviewees for further recommendations on identifying fellow graduating students who would be willing to participate in an interview. I also conducted a second round of interviews in the Spring 2009 semester ending with a total of 48 student interviews (Table 2). Five questions were asked during the interview, with each interview lasting between 25 and 60 minutes. 
Table 2 Student interview sample demographics

\begin{tabular}{llllllll}
\hline & $\begin{array}{l}\text { Under- } \\
\text { graduates }\end{array}$ & $\begin{array}{l}2 \mathrm{yr} \\
\text { March }\end{array}$ & $\begin{array}{l}3.5 \mathrm{yr} \\
\text { March }\end{array}$ & Males & Females & $\begin{array}{l}\text { Racial/ } \\
\text { Ethnic } \\
\text { Minorities }\end{array}$ & $\begin{array}{l}\text { Total } \\
\text { interviews }\end{array}$ \\
\hline School A & 14 & 7 & 8 & 14 & 15 & 9 & 29 \\
\hline School B & 10 & 4 & 5 & 10 & 9 & 5 & 19 \\
\hline
\end{tabular}

Table 3 Faculty interview sample demographics

\begin{tabular}{llllllll}
\hline & Adjunct & $\begin{array}{l}\text { Tenured/ } \\
\text { tenure- } \\
\text { track }\end{array}$ & Male & Female & $\begin{array}{l}\text { Racial/ } \\
\text { Ethnic } \\
\text { minority }\end{array}$ & $\begin{array}{l}\text { Total } \\
\text { interviews }\end{array}$ & $\begin{array}{l}\text { Total } \\
\text { possible }\end{array}$ \\
\hline School A & 5 & 7 & 7 & 5 & 1 & 12 & 23 \\
\hline School B & 3 & 7 & 6 & 4 & 2 & 10 & 12 \\
\hline
\end{tabular}

I sent an email request to all architecture faculty (tenured, tenure-track and adjunct) who taught Design Studio at Schools A and B to participate in an interview for research on socialisation in architectural education. Demographics of the final faculty interview samples are listed with a total of 22 faculty interviews (Table 3). Five questions were asked during the interview, with each interview lasting between 40 and 70 minutes.

\section{Findings}

In order to categorise students according to differences in cultural capital, I employed a K-Means Cluster analysis. Cluster analysis is a statistical method used to group individual cases into homogeneous subgroups (Hair et al. 1992). All student responses to the 11 survey questions of cultural capital from both schools were included in the cluster analysis, producing both two-cluster and three-cluster solutions. The two-cluster solution produced two distinct groups, one with consistently higher mean responses to cultural capital measures and one with consistently lower mean responses to cultural capital measures. Although at first this solution might have seemed most useful for this research question, the three-cluster solution offered a richer, more nuanced description of the students. In the three-cluster solution, unexpected differences emerged between Clusters 1 and 2, which were lost in the two-cluster solution that only produced a simple dichotomy of high vs low cultural capital. The three-cluster solution produced enough differentiations among the three groups that I selected it as the preferred solution.

The final cluster centres (mean responses) for the 11 cultural capital measures of the threecluster solution are graphically displayed in Figures 1-3. Cluster 3 shows the most clear and consistent pattern in that it has the highest mean responses on all 11 variables; this cluster can confidently be conceptualised as High cultural capital. One might expect with a three-cluster solution that if Cluster 3 students represent High cultural capital that Clusters 1 and 2 would fit into either the categories of Low or Medium cultural capital, but that is not the case. On some items, the two clusters have similar means and on other items, they answer quite differently. It is the differentiations in responses between Clusters 1 and 2 on a number of items, e.g. Dance classes and Encouraged to read books by parents, that reinforces the selection of a three-cluster solution over a two-cluster solution. 


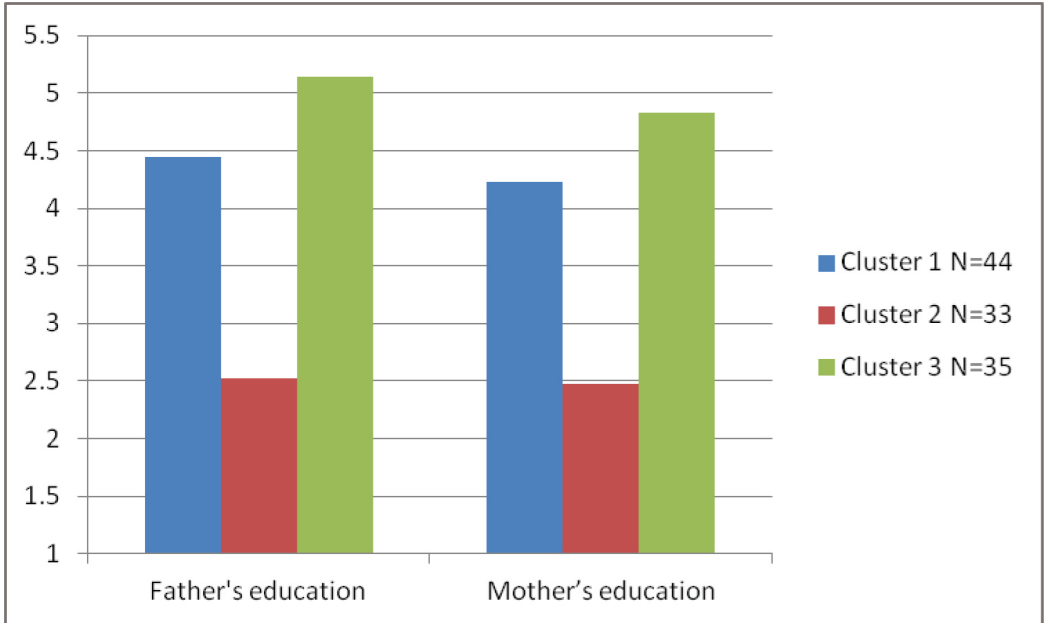

15

Jennifer

Chamberlin Payne
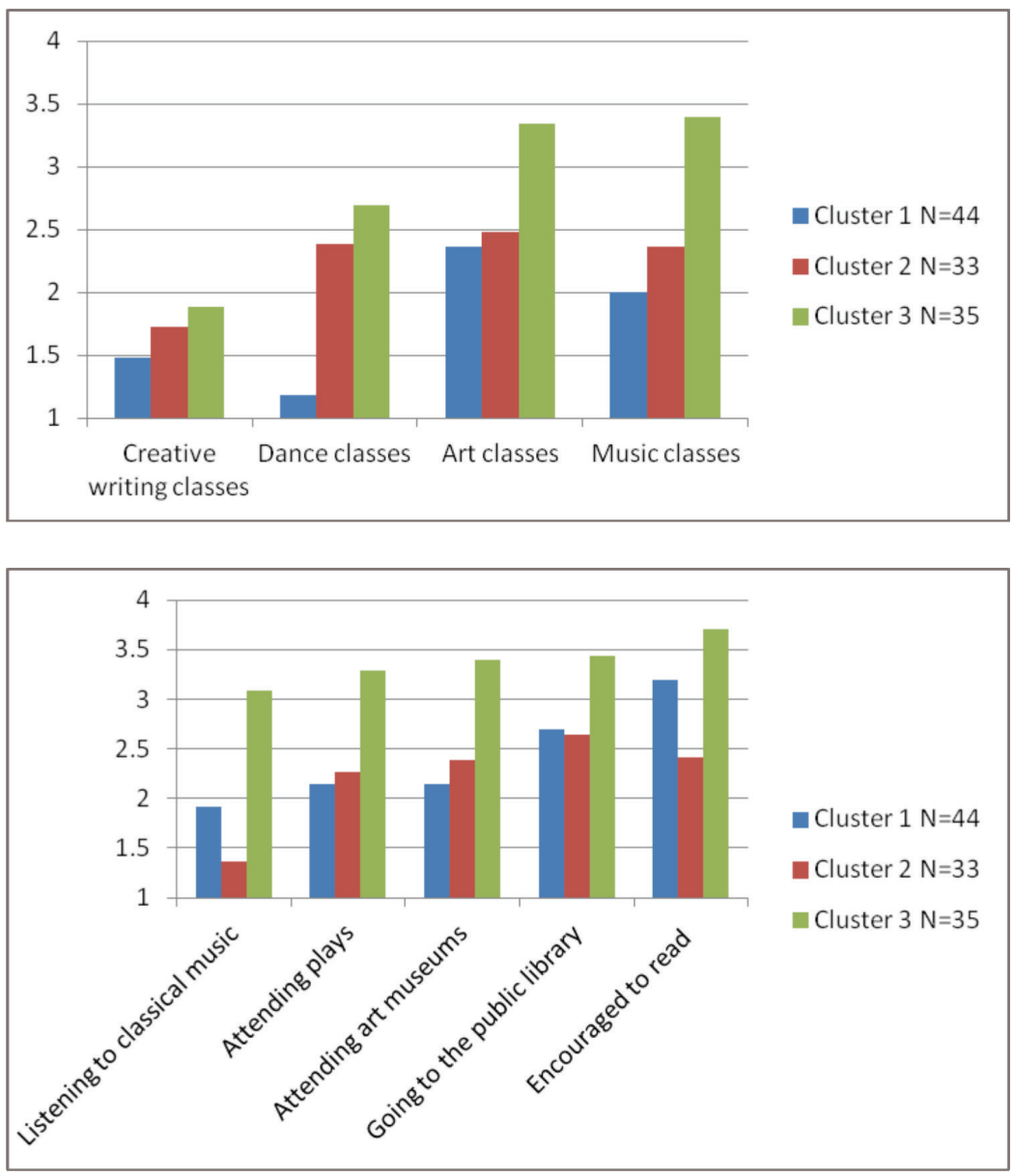

This page:

Figure 1

Final cluster centers (Mean responses) to questions of level of parental education. Response choices: 1 =Some elementary or high school, $2=$ High school graduate, $3=$ Some college, $4=$ College graduate, $5=$ Some graduate school, 6=Graduate /

Professional degree

Figure 2

Final cluster centers (mean responses) for childhood participation in extracurricular classes. Response choices: $1=$ Never, $2=$ One-two times, $3=$ Three-four times, $4=$ Five or more times

Figure 3

Final cluster centers (mean responses) for childhood participation in activities requiring parental involvement. Response choices:

$1=$ Not at all,

$2=$ Only occasionally, $3=$ Somewhat frequently, 4=Quite often 


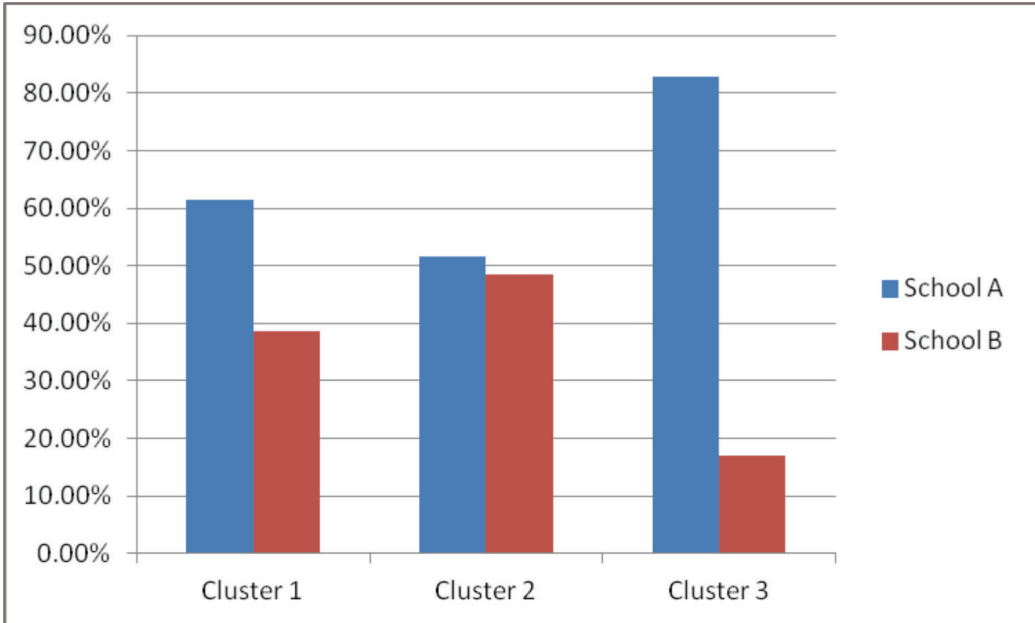

Cluster demographics at each case study site The student samples of Schools A and B are distributed quite differently among the three clusters (Figure 4). Cluster 3 is overwhelmingly represented by School A students, constituting over 80 per cent of that cluster; the chi-square analysis for this distribution is statistically significant $\left[X^{2}=7.816, d f=2, p=0.02\right]$. The chi-square statistic is used to determine if there is a relationship between two categorical variables; in this research the variables are 'Cluster membership' and 'School'.

Formatting the data from Figure 4 in such a way to examine how the clusters are distributed within each school, clear differences emerge between the schools (Figures 5-6). Clusters 1 and 3 each represent a little more than one-third of the student sample at School A, with Cluster 2 students (those from a presumably less culturally privileged background) having the smallest representation there. At School B, Clusters 1 and 2 constitute approximately the same proportion, and Cluster 3 (those from a presumably more culturally privileged background) has the smallest representation there.

\section{Survey questions of organisational habitus} In addition to documenting the organisational habitus of each case study site through measures of university resources, graduation rates, and entering GPA and SAT scores, there were two survey questions that also defined each school's organisational habitus. The first question asked students to evaluate the extent to which 14 particular subject areas were emphasised in their curriculum, with choices on a fourpoint scale: (1) Not at all emphasised, (2) Minimally emphasised, (3) Somewhat emphasised and (4) Strongly emphasised. Mean responses to this question of Perceived Curriculum from the two schools were overall quite similar with the largest difference being between their perceptions of emphasis on Theory and Criticism, with School A students perceiving much more emphasis than School B students (Figure 7). Out of 14 items, seven produced statistically significant differences between School A and B students in one-way analysis of variances (ANOVAs) with $p<0.05$ and are marked with asterisks (Figure 7). ANOVAs are used to determine if there is a statistically significant difference between two groups' mean responses (School A and B).

The other survey question that contributed to defining the organisational habitus of each architecture programme related to the students' college choice intentions, which has been a subject of interest to researchers who have used a Bourdieuian framework in the study of higher education (McDonough 1997; Hossler et al. 1989). The survey question asked, 'What initially attracted you to this particular university?' Students were given a list of 13 items from which to select their top three reasons. Responses are 

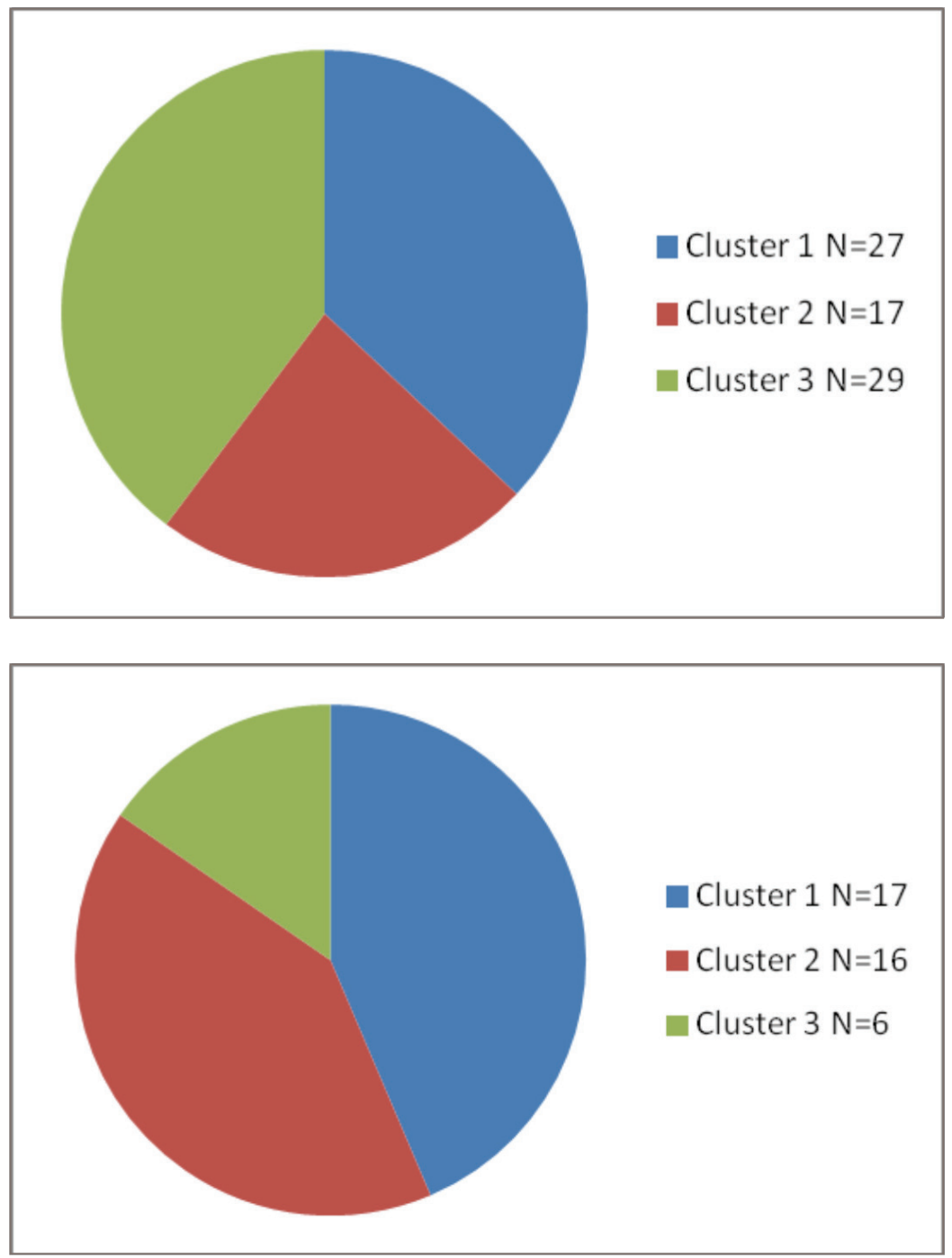

Opposite page:

Figure 4

Distribution by school within each cluster

This page:

Figure 5

Distribution by cluster within School A

Figure 6

Distribution by cluster within School B

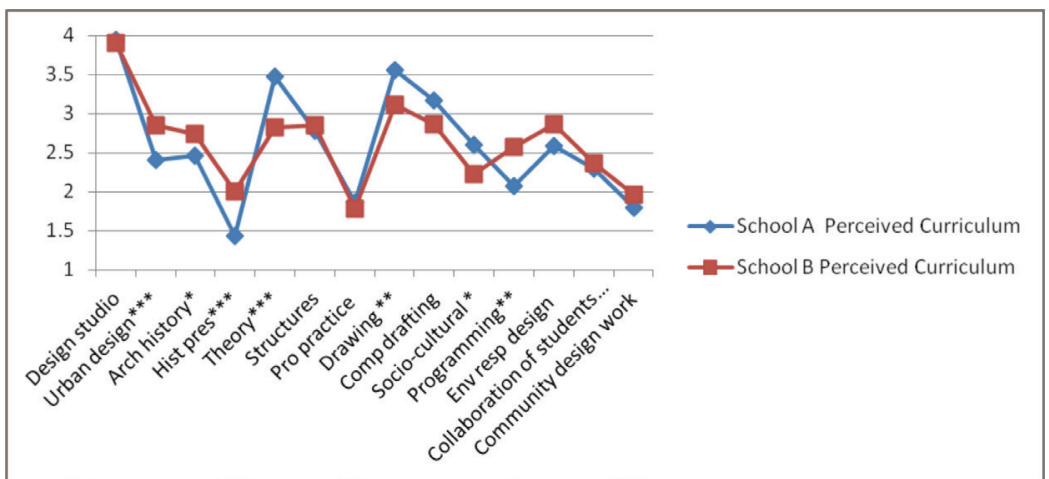

Figure 7

Comparison of

School A and B survey responses to curricular emphases in aggregate form ${ }^{*}: \mathrm{p}<0.05,{ }^{* *}$ : $p<0.01$, *** $p<0.005$. Response choices: $1=$ Not at all emphasized, 2=Minimally emphasized, $3=$ Somewhat emphasized, $4=$ Strongly emphasized 
18

Jennifer

Chamberlin Payne

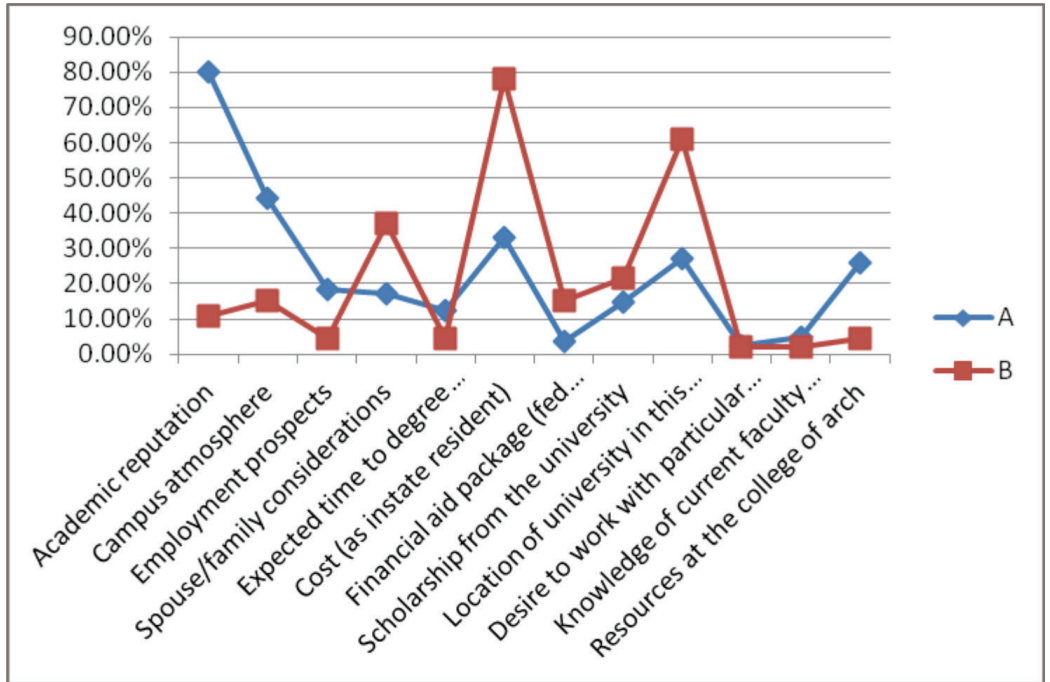

given in aggregate form for each school to compare overall percentages for both schools (Figure 8). Clearly, School A students are drawn to their university primarily because of its academic reputation, which is in great contrast to School B students who attended their university primarily because of cost.

\section{Survey questions of Satisfaction, Studio Experiences and Problematic Experiences} When cluster responses were compared within each school to survey questions of Satisfaction, Studio Experiences and Problematic Experiences, there was a consistent pattern of more negative responses from Cluster 1 students at both schools. Overall, all of School B's responses were more negative than School A's responses, but School B's Cluster 1 responses were still markedly more negative than School B's Clusters 2 and 3 . All statistically significant differences $(p<0.05)$ from one-way ANOVAs for the two schools on the 50 questions of Satisfaction, Studio Experiences and Problematic Experiences are listed (Figures 9-10).

\section{Multi-dimensional scaling}

The one-way ANOVAs were followed up with a multi-dimensional scaling (MDS) procedure to further understand how the clusters related to each other both within and between schools. In
MDS analyses, points that are closer to one another are interpreted as having similarities in their patterns of response. The eight points in the plot represent mean responses for the three clusters at each school and as well as overall mean responses for each of the entire School A and School B samples to questions of Problematic Experiences (Figure 11). There are three key points to make when interpreting this MDS plot. Firstly, there are two distinct regions for School A and School B, as indicated by the dashed line in Figure 11. Secondly, the School A cluster points are much closer to each other and their overall mean than the School B clusters are to each other. Thirdly, although the School A points are closer to each other than the School B points, School A's Cluster 1 is clearly separate from School A's Clusters 2 and 3 and Overall mean.

Although none of the one-way ANOVAs were statistically significant for these items of Problematic Experiences, both schools' Cluster 1 students generally reported experiencing more frequent problems than Cluster 2 or 3 students. The most frequent problem reported by any group at School A was Cluster 1 on Financial problems with a mean response of 2.54 which falls in between Only Occasionally and Somewhat frequently. The highest mean response at School B to questions of Problematic experiences was Cluster 1's response of 3.18 to the 


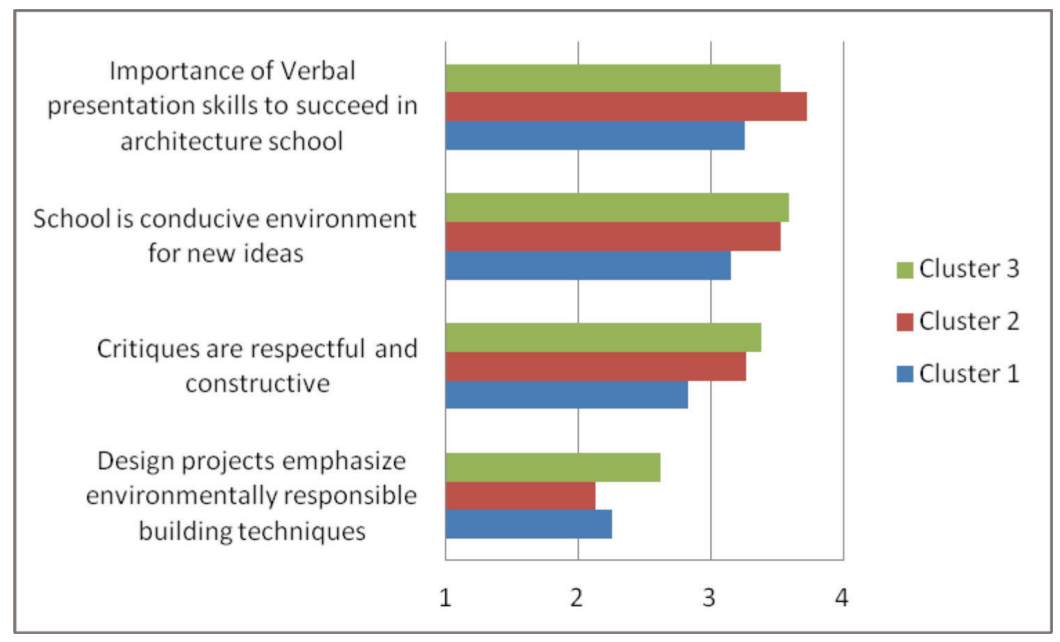

Lack of positive communication $\mathrm{w} /$ program director

Lack of support from administrative staff

How satisfied with faculty's ability to provide inspiration? $* *$

How satisfied with faculty's currency in field?

How satisfied with your choice of arch at this university?

Critiques are respectful and constructive

Instructors accept diverse thinking
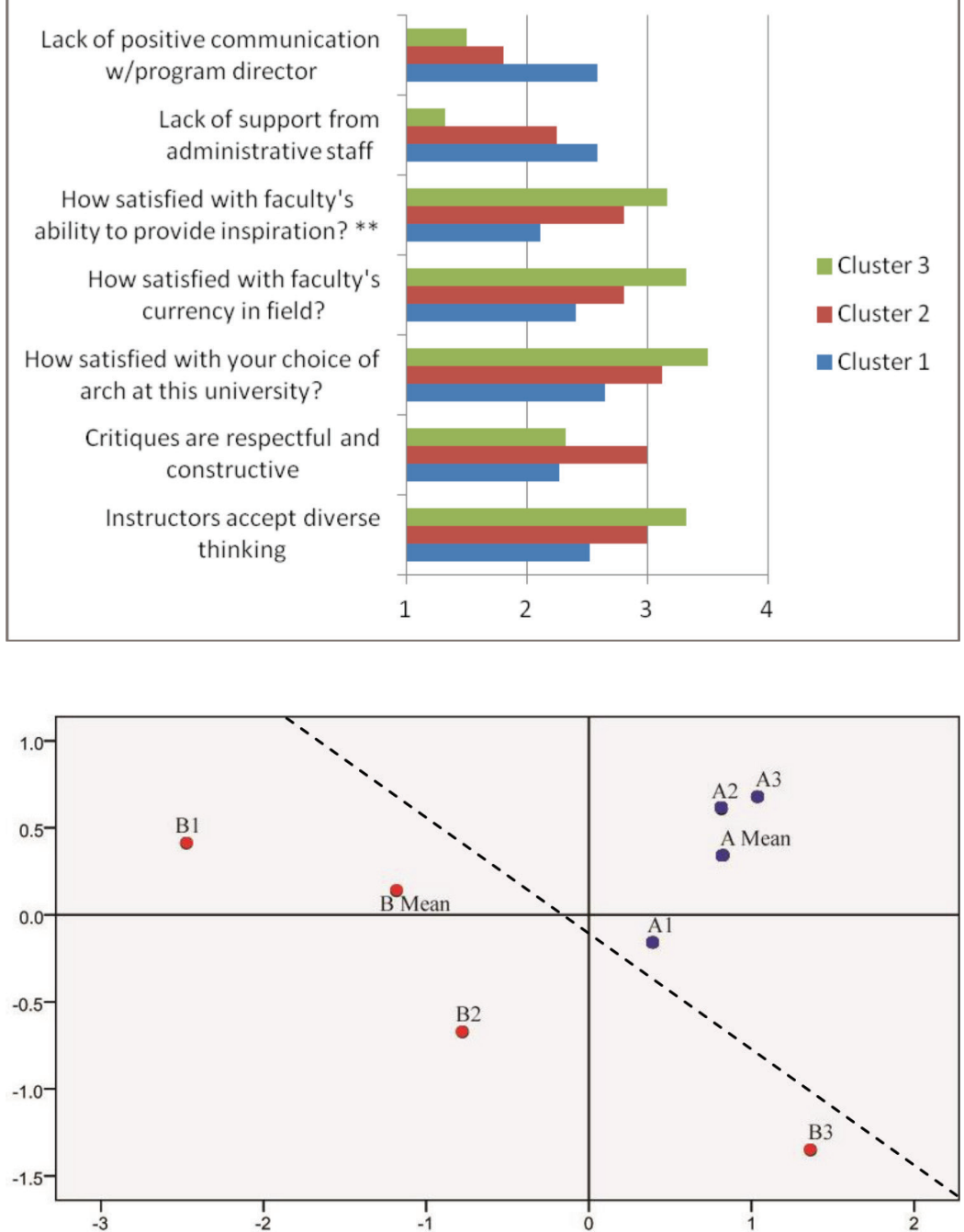

19

Jennifer

Chamberlin Payne

Opposite page:

Figure 8

What attracted you to this university

comparing samples

of School A and

School B

This page:

Figure 9

School A statistically significant differences among clusters on one-way Anovas $(p<0.05)$ on questions of Satisfaction, Studio Experiences and

Problematic

Experiences.

Response choices:

$1=$ Not at all/Strongly disagree, $2=$ Only occasionally/

Somewhat disagree, $3=$ Somewhat

frequently/Somewhat agree, 4=Quite often/ Strongly agree

Figure 10

School B statistically significant differences among clusters on one-way Anovas $(p<0.05)$ on questions of Satisfaction, Studio Experiences and Problematic

Experiences.

Response choices: $1=$ Not at all/Strongly disagree, $2=$ Only occasionally/

Somewhat disagree, $3=$ Somewhat frequently/Somewhat agree, 4= Quite often/ Strongly agree ${ }^{* *} \mathrm{p}<0.005$

Figure 11 MDS plot by cluster means on questions of Problematic Experiences Stress $=0.04135$ $\mathrm{RSQ}=0.99096$ 
item Lack of positive contact with the dean, meaning that these students reported this problem happening more often than Somewhat frequently.

The findings reported thus far have relied upon results from quantitative measures to illustrate two points: one, when examining differences between schools, there is a relatively greater dissatisfaction of School B students compared to School A students and two, when examining differences within each school, Cluster 1 students report a greater frequency of problems and higher levels of dissatisfaction in their educations. Results from qualitative data collected in interviews with School A and B faculty offer another perspective to examine the dynamics specific to each school as well offering insight into the interaction of students' habiti with their respective architecture programme's organisational habitus.

\section{Interviews with faculty}

One interview question in particular prompted faculty carefully to consider who the students are in their programme and how they fit in within the larger system of architectural education: 'How important do you think students' backgrounds are, for example, their artistic, cultural or educational backgrounds?' About 75 per cent of both schools' faculty responded that they believed their students' backgrounds to be 'very important' in shaping students' educational experiences.

One School A tenure-track studio instructor (undergraduate and masters' level), Mira, discussed having two types of students during her eight years of teaching at School A (all interviewees have been assigned pseudonyms). She described one group of students who had grown up in the state in which School A is located and have never left the state, but were brought up with a mentality to be open to everything, 'they absorb everything open-mindedly'. In contrast, the other group she described included those students who have been raised by 'travelling to Switzerland every winter to go skiing and they are so closed-minded, it's unbelievable'. Another School $A$ adjunct studio instructor (undergradu- ate), Mark, echoed Mira's sentiment that students' financial and cultural upbringing is not nearly as important as their curiosity, desire to learn and openness to new ways of thinking. In his experiences, some of his best students have been from the 'backwoods and have never even seen a city with two stoplights', but have an inventive, creative, problem-solving ability that has flourished nonetheless.

Michelle, a tenured studio instructor (undergraduate), who had been teaching at School A for over 15 years, raised the issue of how a student's background may hinder him or her from fitting into the culture of architecture. She proposed that there is an 'elitist air around architecture', where 'it is its own little world and some students have a much easier time slipping into that or at least pretending they are part of it and some have a much harder time feeling like they can start to talk about anything'. Michelle speculated that those students who have encountered more difficulties 'slipping' into this world are those who perceive architecture as a 'scientific, technical, puzzle solving endeavour' and resist it being 'an abstract endeavour'. In her teaching experience, such students were more likely to 'come from a culture where things are more direct, you know what they are and you are getting through them day by day'. This is in contrast with the students she has witnessed who embrace architecture as 'an abstract endeavour' and likely 'come from a culture where metaphors are a part of life experience'.

School B faculty did not make as explicit connections between students' backgrounds and educational experiences as the majority of School A faculty did. In contrast to School A, interview responses among School B faculty had a slightly negative tone when discussing their students. Several instructors felt that the state in which School B is located lacked in resources and interesting works of architecture for students to experience. One undergraduate instructor described in-state students as

at a disadvantage. There's not a lot of great architecture to look at or a different kind of architecture [in this state]. There's a sameness to everything. 
So they can't imagine that a door could be any other size than a standard door. They just can't imagine; their imaginations are stunted.

Other undergraduate studio instructors at School B discussed a lack of initiative that they observed in their students. A tenure-track 400 level studio instructor expressed her frustration with her students who were 'not necessarily willing to go [to the library] and pull out a book to see how they can better their own project, but are instead relying solely on professors to see what the professors can give them'. Another part-time undergraduate instructor echoed this sentiment about her students: 'they think the internet is God ... and I think a lot of them haven't even been to a library'. These negative perceptions of students were not unique to undergraduate instructors at School B. Garrett, a tenured graduate student instructor, did recognise a few 'outstanding' students in the recent past, but even they were described as 'self-limiting'. Speaking of these students, he said that

they really could push themselves further out there in terms of being a designer and open themselves up to the possibilities. [But] for whatever reason ... they don't want to press it and I'm somewhat disappointed. I understand because maybe if they really were that student they' $d$ be off at Columbia [University] or somewhere really pressing themselves to the limits.

The contrast in the faculty interview excerpts between Schools A and B are indicative of how differently each school's faculty perceives its students and contribute to differences between the schools' organisational habiti. One definition of organisational habitus as 'a pervasive stream of beliefs, expectations and practices that flow through a school' underscores the importance of faculty perceptions of students in this research (Diamond et al. 2004, 76). The slightly disappointed tone with which the majority of School B faculty used in describing their students is an indicator of an organisational habitus that is marked by lowered expectations and a belief that their students are limited to some extent by their circumstances. At School A, faculty responses reflected high expectations regardless of a student's background with a perception that the most important characteristic an architecture student can have is an openness and willingness to learn.

\section{Discussion}

This work highlights the importance of student backgrounds, specifically their habitus or levels of cultural capital, in shaping student experiences in architectural education. Previous research in architectural education has focused exclusively on race and/or gender (e.g. Anthony 2002; Frederickson 1993), whereas the present work accounts for a more comprehensive understanding of architecture students. Furthermore, in considering students' levels of cultural capital, students could not be categorised simply into 'low' and 'high' cultural capital groups, which resulted in a more nuanced conceptualisation of student backgrounds. An unexpected third group (Cluster 1) emerged from the analysis, which encompassed similar attributes to both the 'low' and 'high' cultural capital student groups. This group of students was the most dissatisfied at both schools. Even though I cannot make claims to explain such dissatisfaction in this particular group based on the present data analysis, the fact that such a group emerged is a call to raise awareness and recommend new directions for the future of architectural education, specifically considering the importance of students' cultural capital.

\section{Limitations of the study}

In selecting a case study strategy, employing both quantitative and qualitative tactics, this research sought to produce a comprehensive evaluation of two schools of architecture. Nevertheless, every research strategy has its limitations. There were three key limitations specific to this study, that ideally future research could address: (1) This research provided a snapshot at one particular point in time, unable to track changes over time as a longitudinal design could. (2) It would have been desirable to conduct more inferential statistics such as
Jennifer

Chamberlin Payne 
MANOVAs to quantitatively document the interaction of cluster with gender, programme type, race and ethnicity, but small sample size was prohibitive for such analyses. (3) Each case study site was only representative of a particular type of university, that is, School A known as a public ivy and School B as a less selective university.

\section{Implications of research}

This research found clear evidence that the habitus of both students and the schools in which they study matter in shaping students' experiences in architectural education. Considering this interaction of a student's habitus with the organisational habitus of his or her architecture school, it is understandable that some students will quite readily feel a match between themselves and their architecture programme, and for other students it will be a more difficult process to find common ground between themselves and their programme. Following this sentiment, I suggest two key implications for architectural faculty and administrators to consider, based on the findings from this research.

\section{Implication one: diverse student populations}

There has been a fair amount of attention devoted to identifying the issue of a lack of diversity in the architectural profession and even some well-intentioned initiatives to attract minority youths to the discipline (e.g. Charter High School of Architecture \& Design in Philadelphia), but yet the numbers of women and minorities practising in the profession are still grim. Various explanations have been offered regarding the particular barriers to women and minorities in entering architecture, including lack of visibility, lack of support and lack of sensitivity to particular needs (DeGraft-Johnson et al. 2005; McCann 2007). I am expanding on this previous research by focusing solely on the education of future architects, urging architectural educators and administrators to ask themselves 'What does the discipline of architecture have to offer to people of a diverse background?' One School A faculty member, prompted a discussion on this topic in his interview, recognising that the select aspects that architecture privileges (i.e. theory and design) may not be of interest to a broad spectrum of people. Building upon his sentiment, architectural education could 'rein in' the present studio-dominated curricular hierarchy to validate other worthy aspects of its curriculum, potentially to present itself as an attractive possibility to people of various backgrounds and interests. Even beyond curricular reform, it is more the niche that architecture has carved out for itself that needs reform, as more concerned with architects being arbiters of taste rather than members of a professional body that holds valuable expertise in pressing issues such as environmentally sustainable design, housing and infrastructure (Brain 1991; Fisher 2004; Boyer \& Mitgang 1996).

\section{Implication two: self-assessment for each school}

In demonstrating the importance of students' cultural capital in this research, I have highlighted how such a factor interacted differently at two case study sites with two different organisational habiti. The recommendation to other architecture schools is to complete a self-assessment of the dynamics particular to their programme, identifying the larger context of organisational habitus in which such interactions play out. There cannot be a 'one size fits all' recommendation for architectural education from this research, for it demonstrated the importance of considering and understanding particular student populations; furthermore, it emphasised the need to investigate the extent to which students' values and interests mesh with those of their education. It is the responsibility of each architecture school to identify the problematic issues specific to their programme; this research design offers a set of tools for them to do so.

\section{Conclusion}

The purpose of this research is strongly to urge schools of architecture to know their students, to understand their students' values and to identify where points of conflict may lie between their mission as an architecture school and their students' desires and expectations as architecture students. I am not advocating that architec- 
ture schools should employ a simple approach of catering to their students' every whim and desire; rather I am suggesting that schools recognise the differences between their intentions as an architecture programme and their students' values, ultimately leading to asking 'How can such differences be addressed?' If students' interests and values in architectural education are at least recognised and understood and therefore validated, then faculty and administration can make an effort to engage all students on a common meeting ground.

Jennifer Chamberlin Payne received her PhD in Architecture from the University of Michigan in December 2010 and is presently a part-time faculty member for Kaplan Test Preparation in Albuquerque, NM. She received the Architectural Research Centers Consortium (ARCC) King Student Medal for her dissertation research on socialisation in architectural education. She received her Master's degree in Architecture from the University of New Mexico in 2003. Contact address: 707 Fruit Ave NW, Albuquerque, NM 87102, USA. Email: jlcpayne@gmail.com

\section{References}

American Institute of Architects (2004) Diversity in the Architecture Profession (online). Available at: http://aia.org/aiaucmp/groups/aia/documents/pdf/aias077643.pdf (accessed 11 January 2012)

Anthony, K. H. (2002) Designing for diversity: implications for architectural education in the twenty-first century, Journal of Architectural Education, Vol. 55, No. 4, pp. 257-67

Aschaffenburg, K. \& Maas, I. (1997) Cultural and educational careers: the dynamics of social reproduction, American Sociological Review, Vol. 62, No. 4, pp. 573-87

Bourdieu, P. (1977) Cultural reproduction and social reproduction, in J. Karabel \& A. H. Halsey [Eds] Power and Ideology in Education. New York: Oxford University Press, pp. 487-511
Bourdieu, P. (1996) The State Nobility: Elite Schools in the Field of Power. Cambridge: Polity Press

Boyer, E. L. \& Mitgang, L. D. (1996) Building Community: A New Future For Architecture Education and Practice. Princeton: Carnegie Foundation

Brain, D. (1991) Practical knowledge and professional control: the professionalization of architecture in the U.S., Sociological Forum, Vol. 6, No. 2, pp. 239-68

DeGraft-Johnson, A., Manley, S. \& Greed, C. (2005) Diversity or the lack of it in the architectural profession, Construction Management and Economics, Vol. 23, No. 10, pp. 1035-43

Diamond, J. B., Randolph, A. \& Spillane, J. P. (2004) Teachers' expectations and sense of responsibility for student learning: the importance of race, class and organizational habitus, Anthropology and Education Quarterly, Vol. 35, No. 1, pp. 75-98

Dobbin, F. (2008) The poverty of organizational theory: comment on: Bourdieu and organizational analysis, Theory and Society, Vol. 37, No. 1, pp. 53-63

Dumais, S. (2002) Cultural capital, gender, and school success: the role of habitus, Sociology of Education, Vol. 75, No. 1, pp. 44-68

Fisher, T. (2004) Architects behaving badly, Harvard Design Magazine, No. 21, pp. 1-3

Frederickson, M. (1993) Gender and racial bias in design juries, Journal of Architectural Education, Vol. 47, No. 1, pp. 39-49

Groat, L. N. \& Ahrentzen, S. A. (1996) Reconceptualizing architectural education for a more diverse future: perceptions and visions of architectural students, Journal of Architectural Education, Vol. 49, No. 3, pp. 166-83

Hair, J., Anderson, R. \& Tatham, R. (1992) Multivariate Data Analysis with Readings. New York: Macmillan 
Hearn, J. (1984) The relative roles of academic, ascribed and socioeconomic characteristics in college destinations, Sociology of Education, Vol. 57, No. 1, pp. 22-30

Horvat, E. M. \& Antonio, A. L. (1999) 'Hey, those shoes are out of uniform': African American girls in an elite high school and the importance of habitus, Anthropology and Education Quarterly, Vol. 30, No. 3, pp. 317-42

Hossler, D., Braxton, J. \& Coopersmith, G. (1989) Understanding student college choice, in J. C. Smart [Ed.] Higher Education: Handbook of Theory and Research, Volume V. New York: Agathon Press, pp. 231-88

Karabel, J. \& Halsey, A. H. [Eds] (1977) Power and Ideology in Education. New York: Oxford University Press

Kingston, P. W. \& Lewis, L. S. (1990) The High Status Track: Studies of Elite Schools and Stratification. New York: State University of New York Press

May, L. (2004) Building in color: UC tries to find more black students who want to be architects (online). Available at: http://cincinnati.bizjournals. com/cincinnati/stories/2004/02/02/story5.html (accessed 9 January 2012)

McCann, H. (2007) 0.2\%, Architect, Vol. 96, No. 3, pp. $62-5$

McDonough, P. M. (1997) Choosing Colleges: How Social Class and Schools Structure Opportunity. Albany: State University of New York Press

Reed-Danahay, D. (2005) Locating Bourdieu. Bloomington: Indiana University Press

Spreckelmeyer, K. F., Domer, D. E. \& Carswell, J. W. (1985) Measuring curricular orientation in architectural education, Journal of Architecture and Planning Research, Vol. 2, No. 2, pp. 99-114

Stevens, G. (1995) Struggle in the studio: a Bourdivin look at architectural pedagogy, Journal of Architectural Education, Vol. 49, No. 2, pp. 105-22
Stevens, G. (1998) The Favored Circle. Cambridge, MA: MIT Press

Swartz, D. (1997) Culture and Power: The Socio/ogy of Pierre Bourdieu. Chicago: University of Chicago Press

US News World Report (2007) Rankings and Reviews (online). Available at: http://colleges. usnews.rankingsandreviews.com (accessed 8 June 2008)

Yin, R. K. (1994) Case Study Research: Design and Methods, second edn. Thousand Oaks, CA: Sage 